\title{
Artikel
}

\section{Wat brengt de Wet bescherming erfgenamen tegen schulden?}

\author{
Mr. L.A.G.M. van der Geld*
}

\section{Inleiding}

Op 1 september 2016 is de Wet bescherming erfgenamen tegen schulden (34224) in werking getreden. ${ }^{1}$ Met de wet wordt beoogd twee knelpunten uit de erfrechtpraktijk weg te nemen. ${ }^{2}$ In verband hiermee is de aanvaardingsfictie van artikel 4:192 van het Burgerlijk Wetboek (BW) angepast en is er een nieuw artikel 4:194a $\mathrm{BW}$, op grond waarvan erfgenamen machtiging aan de kantonrechter kunnen vragen voor beneficiaire aanvaarding voor onverwachte schulden. ${ }^{3}$

* Mr. L.A.G.M. van der Geld is juridisch directeur van Netwerk Notarissen, kandidaat-notaris en docent aan het Centrum voor Notarieel Recht van de Radboud Universiteit Nijmegen.

1. Deze wet wordt ook wel de Wet BETS genoemd. Aanleiding voor de wet is onder meer het rapport 'Erven zonder financiële zorgen' van Netwerk Notarissen en het Centrum voor Notarieel Recht van de Radboud Universiteit Nijmegen.

2. Kamerstukken II 2014/15, 34224, 3 en Kamerstukken II 2015/16, 34224, 5: de knelpunten zijn dat erfgenamen door gedragingen onbewust een nalatenschap zuiver aanvaarden en dat zij dientengevolge door een onverwachte schuld onbedoeld met privévermogen aansprakelijk kunnen worden voor een schuld van de nalatenschap.

3. In deze bijdrage wordt niet ingegaan op de vraag of deze wet voldoende bescherming biedt en of de keuze voor route 3 in het rapport 'Erven zonder financiële zorgen' de meest gelukkige was. Hierover onder meer J.W.A. Biemans, Wetsvoorstel BETS beter dan BETOS, maar helaas (nog) geen standaard beneficiaire aanvaarding, WPNR 2015/7083, E.A. de Jong, Reactie, WPNR $2016 / 7100$ en F. Schols, Reactie, WPNR 2016/7101.

\section{Aanvaardingsfictie van artikel 4:192 BW}

Artikel 4:192 BW heeft een nieuw lid 1 (anvaardingsfictie) gekregen:

'Een erfgenaam die zich ondubbelzinnig en zonder voorbehoud als een zuiver aanvaard hebbende erfgenaam gedraagt doordat hij goederen van de nalatenschap verkoopt, bezwaart of op andere wijze aan het verhaal van schuldeisers onttrekt, anvaardt daardoor de nalatenschap zuiver, tenzij hij zijn keuze reeds eerder heeft gedaan.'

Volgens de memorie van toelichting brengt dit nieuwe lid verduidelijking wanneer sprake is van een erfgenaam die zich ondubbelzinnig en zonder voorbehoud als een zuiver aanvaard hebbende erfgenaam gedraagt. ${ }^{4}$ De minister meent dat er veel onduidelijkheid is over welke gedragingen leiden tot zuivere aanvaarding van een nalatenschap en daardoor wordt 'soms te snel aangenomen dat sprake is van zuivere aanvaarding door een erfgenaam zonder dat hij daarop bedacht is'. De nieuwe bepaling moet voorkomen dat erfgenamen onbewust een nalatenschap zuiver aanvaarden. Daarom zijn, zo valt te lezen in de memorie van toelichting, de gedragingen verduidelijkt en beperkt. In lid 1 zijn nu gedragingen opgenomen die leiden tot benadeling van schuldeisers door nalatenschapsgoederen op welke wijze dan ook aan het verhaal van schuldeisers te onttrekken: 'Artikel 4:192 lid $1 \mathrm{BW}$ is bedoeld om schuldeisers te beschermen tegen benadeling door erfgenamen. ${ }^{5}$

4. Kamerstukken II 2014/15, 34224, 3

5. Kamerstukken II 2015/16, 34224, 5. 
Volgens de minister is in lid 1 geen limitatieve opsomming gegeven, maar worden voorbeelden genoemd van gedragingen die zuivere aanvaarding van een nalatenschap tot gevolg hebben. ${ }^{6}$ Het uitgangspunt in het erfrecht is volgens de minister dat een erfgenaam, voordat hij een keuze maakt over het wel of niet aanvaarden van de nalatenschap, slechts het beheer over de nalatenschap dient te voeren om benadeling van boedelschuldeisers te voorkomen. Dit beheer in het belang van de nalatenschap brengt geen zuivere aanvaarding met zich. ${ }^{7}$ Met andere woorden: zodra de erfgenaam buiten de beheersbevoegdheden treedt ten aanzien van de goederen van de nalatenschap is sprake van zuivere aanvaarding. Dit geldt niet als de erfgenaam zijn keuze reeds eerder heeft gedaan.

\subsection{Gedragingen die vallen onder de aanvaardingsfictie}

In het algemeen vallen alle beschikkingshandelingen die ertoe leiden goederen van de nalatenschap aan het verhaal van schuldeisers te onttrekken onder de aanvaardingsfictie. ${ }^{8}$ In de parlementaire stukken zijn verschillende voorbeelden opgenomen van gedragingen die leiden tot zuivere aanvaarding in de zin van het nieuwe artikel 4:192 lid $1 \mathrm{BW}$. Als voorbeeld wordt genoemd de verkoop van de woning van erflater, het vestigen van een (tweede) hypotheek op de woning of het verdelen van de antiekcollectie tussen de erfgenamen. Het gaat aldus om het bewust verrichten van beschikkingshandelingen die zo ingrijpend zijn dat de erfgenaam als 'heer en meester' beschikt over de nalatenschap. ${ }^{9}$

Met het meenemen van een familiefotoalbum uit het huis van de erflater wordt geen zaak aan het verhaal van de schuldeisers onttrokken omdat het album alleen emotionele waarde heeft en geen verhaalsobject is voor de schuldeisers. De erfgenaam die het huis van de erflater met het album onder de arm verlaat, heeft daarmee de nalatenschap niet zuiver aanvaard. Ook bij het ontruimen van de woning is geen sprake van zuivere aanvaarding, mits de inboedel tijdelijk wordt opgeslagen en beschikbaar wordt gehouden voor schuldeisers. ${ }^{10} \mathrm{De}$

6. Kamerstukken II 2015/16, 34224, 5 .

7. Kamerstukken II 2014/15, 34224, 3 en Kamerstukken II 2015/16, 34224, 5: goed beheer van de nalatenschap kan ook inhouden dat een erfgenaam goederen van de nalatenschap moet verkopen, bijv. goederen die beperkt houdbaar zijn. Als de erfgenaam de opbrengst van de verkoop van deze goederen apart houdt, is geen sprake van zuivere aanvaarding

8. Kamerstukken II 2014/15, 34224, 3, p. 9-10: er wordt voortaan een onderscheid gemaakt tussen handelingen verricht in het kader van het beheer van de nalatenschap die niet tot zuivere aanvaarding leiden en beschikkingshandelingen waarmee een erfgenaam verhaalsobjecten uit de nalatenschap haalt, waardoor schuldeisers worden benadeeld.

9. Kamerstukken II 2014/15, 34224, 3, p. 10.

10. Met deze handelingen wordt volgens de MvT ook niet zuiver aanvaard, Kamerstukken II 2014/15, 34224, 3, p. 10 :

- het uit eigen middelen een rekening van de overledene betalen om een incassoprocedure te voorkomen;

- het in rechte een schuld van erflater betwisten, bijv. omdat de erfgenaam in de administratie bewijs heeft aangetroffen dat deze schuld al is betaald;

- het veiligstellen van kostbaarheden van de overledene door deze in de kluis van de erfgenaam op te bergen. waardeloze inboedel kan worden weggegooid of meegegeven aan de kringloop en leidt niet tot het onttrekken van goederen aan het verhaal van schuldeisers. De leden van de VVD-fractie in de Tweede Kamer vroegen de minister op welke wijze een erfgenaam kan vaststellen of een goed louter emotionele waarde heeft of niet. $\mathrm{Zij}$ noemen het voorbeeld van een oude vaas die achteraf veel geld waard blijkt te zijn. ${ }^{11}$ Het risico van het niet goed inschatten van de waarde van een goed komt voor rekening van de erfgenaam, meent de minister. ${ }^{12}$

\subsection{Hof Den Haag anticipeert}

Het Hof Den Haag wees op 28 juni $2016^{13}$ een arrest waarin werd geanticipeerd op de wet. In de casus van het arrest ging het om de enige erfgename die stelde de pintransacties van de rekening van erflaatster te hebben gedaan in het kader van de uitvaart van erflaatster. De stiefkinderen van erflaatster hebben een vordering van ruim $€ 200.000$. Binnen één maand na het overlijden heeft de erfgename beneficiair aanvaard. Het Hof Den Haag moest oordelen over de vraag of de erfgename door het doen van uitgaven van de bankrekening van erflaatster in de periode ná het overlijden en vóór het beneficiair aanvaarden de nalatenschap zuiver heeft aanvaard. Met verwijzing naar het Koperen Pan-arrest ${ }^{14}$ en de regel van artikel $1095 \mathrm{BW}$ (oud) stelt het hof:

'Handelingen die erop gericht zijn de erflater een passende uitvaart te bezorgen, strekken naar hun aard niet ertoe ten eigen bate over nalatenschapsgoederen te beschikken.'

Het hangt van de omstandigheden van het geval af of sprake is van dit soort handelingen en dit soort kosten. Bij de beantwoording anticipeert het hof op de nieuwe regel van artikel 4:192 BW: zijn door de gedragingen van de erfgename gelden van de nalatenschap onttrokken aan het verhaal van de schuldeisers van de nalatenschap? De erfgename, zo constateert het hof, was zich ervan bewust dat zij betaalde met de pinpas van de rekening van erflaatster en dat er schuldeisers van de nalatenschap van erflaatster, de stiefkinderen, waren. Van een aantal van de pintransacties wordt niet vastgesteld dat deze gelden als redelijke kosten voor een passende uitvaart. De erfgename heeft wat betreft die pintransacties ten eigen bate over de rekening van erflaatster beschikt en daarmee de nalatenschap zuiver aanvaard. Verderop in het arrest merkt het hof nog op dat de erfgename ook door de nieuwe wet niet beschermd zou worden:

'Het gewijzigde artikel 4:192 lid 1 BW beperkt de gedragingen die leiden tot een zuivere aanvaarding van de nalatenschap tot gedragingen die leiden tot een benadeling van schuldeisers door nalatenschaps-

11. Hierbij kan worden gedacht aan het Chinese pot-arrest van HR 12 juli 2013, ECLI:NL:HR:2013:31, in welke casus de erfgenamen de vaas te laag in waarde hadden ingeschat.

12. Kamerstukken II 2015/16, 34224, 5, p. 19.

13. Hof Den Haag 28 juni 2016, ECLI:NL:GHDHA:2016:1985.

14. HR 22 mei 2015, ECLI:NL:HR:2015:1284. 
goederen te verkopen, te bezwaren of anderszins aan het verhaal van schuldeisers te onttrekken.'

\subsection{Het constateren van zuivere aanvaarding door de notaris}

In het kader van het maken van de verklaring van erfrecht informeert de notaris bij de erfgenamen naar hun keuze in de nalatenschap (art. 4:188 lid 1 sub a BW). Tot 1 september 2016 was het gebruikelijk dat de erfgenamen die ervoor kozen de nalatenschap zuiver te aanvaarden een door de notaris opgestelde 'verklaring van zuivere aanvaarding' ondertekenden in plaats van het in artikel 4:191 BW genoemde afleggen van een verklaring van zuivere aanvaarding bij de griffie van de rechtbank. De ondertekening van de verklaring van de notaris kon worden gezien als een gedraging in de zin van artikel 4:192 lid 1 BW (oud) en wordt ook wel informele zuivere aanvaarding genoemd. $\mathrm{Na} 1$ september 2016 staat er echter in artikel 4:192 lid $1 \mathrm{BW}$ kort gezegd dat zuivere aanvaarding geschiedt door te beschikken over goederen van de nalatenschap door ze aan het verhaal van schuldeisers te onttrekken. Artikel 4:191 BW is ongewijzigd, zodat nog steeds de mogelijkheid bestaat om via de griffie van de rechtbank zuiver te anvaarden, met als gevolg betaling van $€ 123$ aan griffierecht. De leden van de CDA-fractie in de Tweede Kamer hebben de minister gevraagd naar de administratieve lasten van de zuivere aanvaarding. ${ }^{15}$ In de nota naar aanleiding van het verslag $^{16}$ laat de minister weten dat een erfgenaam niet naar de rechter hoeft om zuiver te aanvaarden:

'Als een erfgenaam zuiver wil aanvaarden, bijvoorbeeld omdat hij heeft vastgesteld dat de nalatenschap positief is, kan hij in samenspraak met de overige erfgenamen tot afwikkeling van de nalatenschap overgaan. De erfgenamen zullen in dat geval de schuldeisers voldoen. Om alle schuldeisers te kunnen voldoen, zullen zij beschikken over de goederen van de nalatenschap. In dat geval is er sprake van zuivere aanvaarding in de zin van artikel 4:192 lid 1 BW.'

Hoe vertalen we dit naar de praktijk? Door het ondertekenen van de verklaring van zuivere aanvaarding bij de notaris beschikt de erfgenaam niet door het onttrekken van goederen aan het verhaal van schuldeisers. Hij kan wel gaan beschikken in de zin van artikel 4:192 lid 1 BW met een afschrift van de door de notaris afgegeven verklaring van erfrecht. De notaris wil ten behoeve van die verklaring van erfrecht weten wie welke keuze heeft gemaakt. Ik meen dat de praktijk waarin de erfgenaam een verklaring van zuivere aanvaarding van de notaris ondertekent, kan worden gehandhaafd. Ik maak daarbij de volgende kanttekeningen. De tekst van de verklaring wordt aangepast, in die zin dat de erfgenaam het voornemen heeft de nalatenschap zuiver te gaan aanvaarden door het verrichten van beschikkingshandelingen en dat hij niet reeds verworpen dan wel beneficiair anvaard

15. Kamerstukken II 2015/16, 34224, 4 .

16. Kamerstukken II 2015/16, 34224, 5, p. 14. heeft. Dit is een afstand van recht, zoals dit thans ook in de praktijk gebeurt bij de 'verklaring van niet-ongedaanmaking' in de zin van artikel 4:18 BW in het kader van het afgeven binnen drie maanden na overlijden van een verklaring van erfrecht als een wettelijke verdeling aan de orde is. In het boedelregister kan de notaris kort voor het afgeven van de verklaring van erfrecht controleren of er daadwerkelijk niet reeds beneficiair is aanvaard dan wel verworpen.

Omdat erfgenamen maar één keer een keuze kunnen maken omtrent aanvaarden en verwerpen, blijft het nodig in de praktijk te informeren bij de erfgenamen of zij niet reeds aanvaardingshandelingen in de zin van artikel 4:192 lid 1 BW hebben verricht. De kans dat zij dat reeds hebben gedaan voordat zij naar het notariskantoor voor een verklaring van erfrecht komen, is afgenomen. Met een fotoalbum onder de arm het sterfhuis verlaten is immers geen enkel probleem: ${ }^{17}$

'Als wordt vastgesteld dat de erfgenaam handelingen heeft verricht waarbij geen sprake is van beheer, doordat hij bijvoorbeeld een fotoboek van de erflater heeft meegenomen, dan verduidelijkt de zinsnede "doordat hij goederen van de nalatenschap verkoopt, bezwaart of op andere wijze aan het verhaal van schuldeisers onttrekt" of hierdoor sprake is van zuivere aanvaarding.'

\subsection{Aangekondigde reparatie}

De vaste commissie voor Veiligheid en Justitie van de Eerste Kamer liet de minister op 20 juli 2016 weten dat er sprake was van een 'mogelijk foutieve woordkeuze' in artikel 4:192 lid 1 BW (nieuw). Met deze brief vroeg de commissie om een nadere reactie op een eerdere brief van de minister, ${ }^{18}$ waarin hij liet weten dat er geen sprake is van een fout. Het gaat om het woord 'verkopen' in 'doordat hij goederen van de nalatenschap verkoopt', omdat verkopen niet valt onder een beschikkingshandeling, die beoogd is in artikel 4:193 lid $1 \mathrm{BW}$ (de andere genoemde handelingen zijn immers beschikkingshandelingen). Beschikkingshandelingen zijn wel het vervreemden en bezwaren van een goed, maar niet het sluiten van overeenkomsten die daartoe verplichten. Bovendien omvat het woord 'verkopen' niet het sluiten van een schenkingsovereenkomst met betrekking tot een goed van de nalatenschap. De commissie stelt de minister voor om aan te sluiten bij de in artikel 1:88 lid 1 sub a BW gebezigde terminologie voor een correctere formulering: 'overeenkomsten strekkende tot vervreem$\operatorname{ding}(\ldots)$.

De minister reageert op 29 augustus $2016^{19}$ door te stellen dat het nieuwe lid 1 van artikel 4:192 BW een open norm bevat. Er zijn in het lid gedragingen genoemd die naar algemene maatschappelijke opvattingen verder

17. Kamerstukken II 2015/16, 34224, 5, p. 10.

18. Brief van de minister van Veiligheid en Justitie van 6 juli 2016 (Kamerstukken I 2015/16, 34224, C).

19. Ministerie van Veiligheid en Justitie 29 augustus 2016, nr. 787307. 
gaan dan in het kader van een goed beheer van de nalatenschap noodzakelijk is. Het is geen limitatieve opsomming, maar er staan voorbeelden in van gedragingen die een zuivere aanvaarding van een nalatenschap tot gevolg hebben. Zo valt de door de commissie genoemde schenkingsovereenkomst onder 'het op andere wijze aan het verhaal van schuldeisers onttrekken'. De minister herhaalt dat beheershandelingen niet leiden tot een zuivere aanvaarding. Volgens de minister staat de bedoeling van artikel 4:192 lid $1 \mathrm{BW}$ niet ter discussie, maar vindt hij de precieze formulering van de bepaling voor verbetering vatbaar. Daarom wordt bij de eerstvolgende reparatiewet van het ministerie van Veiligheid en Justitie de tekst van artikel 4:192 lid $1 \mathrm{BW}$ verduidelijkt door meer aan te sluiten bij de formulering van artikel 1:88 lid 1 onder a BW, zoals voorgesteld door de commissie.

\section{Onverwachte schulden}

Met artikel 4:194a BW worden erfgenamen beschermd tegen onverwachte schulden van de nalatenschap. Volgens de memorie van toelichting geldt dit artikel alleen in uitzonderingssituaties, het artikel wordt dan ook wel uitzonderingsclausule genoemd. Het biedt bescherming voor de zuiver aanvaard hebbende erfgenaam die wordt geconfronteerd met onverwachte schulden die hij niet kende of behoorde te kennen. ${ }^{20}$ Gedacht moet worden aan de situatie dat een erfgenaam weloverwogen heeft gekozen voor zuivere aanvaarding, omdat hij in eerste instantie heeft vastgesteld dat de baten van de nalatenschap de schulden ruimschoots overtreffen, of hij heeft ervoor gekozen om een kleine schuld van de erflater voor eigen rekening te nemen. ${ }^{21}$ In de rechtspraak werd in een aantal gevallen naar analogie van artikel 4:194 BW dan wel op grond van de redelijkheid en billijkheid voor onverwachte schulden machtiging voor beneficiaire aanvaarding verleend. ${ }^{22}$

De tekst van het nieuwe artikel 4:194a BW luidt als volgt:

'1. Een erfgenaam die na zuivere aanvaarding bekend wordt met een schuld van de nalatenschap, die hij niet kende en ook niet behoorde te kennen, wordt, indien hij binnen drie maanden na die ontdekking het verzoek daartoe doet, door de kantonrechter gemachtigd om alsnog beneficiair te aanvaarden.

2. Wanneer een erfgenaam na vereffening of verdeling van de nalatenschap bekend wordt met een schuld, die hij niet kende en ook niet behoorde te kennen, kan hij de kantonrechter, binnen de in het eerste lid genoemde termijn, verzoeken om te worden ontheven van zijn verplichting de schuld uit zijn vermogen te voldoen voor zover deze niet uit hetgeen hij

20. Kamerstukken II 2014/15, 34224, 3, p. 6

21. Kamerstukken II 2014/15, 34224, 3, p. 7

22. Onder meer: Rb. Limburg 1 februari 2013, ECLI:NL:RBLIM: 2013:BZ0690 en Rb. Assen 19 oktober 2010, TE 2011, afl. 4. krachtens erfrecht uit de nalatenschap heeft verkregen, kan worden voldaan. De kantonrechter verleent deze ontheffing, tenzij de erfgenaam zich zodanig heeft gedragen dat de schuldeiser erop mocht vertrouwen dat de erfgenaam deze schuld uit zijn overige vermogen voldoet.'

Dit artikel biedt twee situaties waarin binnen drie maanden na de ontdekking van de onverwachte schuld bescherming kan worden gevraagd:

- De schuld wordt ontdekt na de zuivere aanvaarding en voordat de verdeling of vereffening van de nalatenschap is afgerond (lid 1).

- De schuld wordt ontdekt na de vereffening of verdeling van de nalatenschap (lid 2).

De erfgenaam die een beroep wil doen op de uitzonderingsclausule wendt zich met een verzoekschrift tot de kantonrechter. Als er een executeur is, dan doet hij het beroep op artikel 4:194a BW omdat hij op grond van artikel 4:145 BW de erfgenamen in rechte vertegenwoordigt. ${ }^{23} \mathrm{Er}$ is daarbij geen toerekening aan de erfgenamen van de bekendheid van de executeur met de schuld; de termijn van drie maanden gaat lopen vanaf het moment dat de erfgenaam bekend wordt met de schuld, hetgeen op zijn laatst is als de executeur hem daarover informeert, al dan niet via de boedelbeschrijving.

Bij een verzoek aan de kantonrechter op grond van lid 1 stelt deze eerst vast of de erfgenaam dit binnen de termijn heeft ingediend. De driemaandentermijn is 'hard'; de kantonrechter verklaart de erfgenaam die zich later meldt niet-ontvankelijk in zijn verzoek. ${ }^{24}$ Vervolgens stelt de kantonrechter vast of het daadwerkelijk om een onbekende schuld gaat. Als dat het geval is, dan machtigt de kantonrechter de erfgenaam om alsnog beneficiair te kunnen aanvaarden.

Op grond van lid 2 kan een erfgenaam in de situatie dat er al is verdeeld of vereffend de kantonrechter verzoeken hem te ontheffen van zijn verplichting de onverwachte schuld uit zijn eigen vermogen te voldoen. Ook hier stelt de rechter eerst vast of het verzoek tijdig is ingediend en of sprake is van een onverwachte schuld. De erfgenaam moet de kantonrechter bewijsstukken overleggen van wat er eventueel beschikbaar is van het geërfde vermogen om de schuld te betalen. Want voor zover de erfgenaam na het betalen van de (andere) schulden uit de nalatenschap heeft verkregen, moet de erfgenaam dat aanwenden voor de betaling van de onverwachte schuld. De ontheffing wordt verleend, tenzij de kantonrechter vaststelt dat de erfgenaam zich zodanig heeft gedragen dat de schuldeiser erop mocht vertrouwen dat zijn vordering zou worden voldaan, omdat de erfgenaam bijvoorbeeld als de erfgenaam na de onttrekking van de schuld de schuldeiser heeft toegezegd deze te betalen. ${ }^{25}$

23. Kamerstukken II 2014/15, 34224, 3, p. 17.

24. Kamerstukken II 2015/16, 34224, 5, p. 25.

25. Kamerstukken II 2014/15, 34224, 3, p. 19. 


\subsection{Welke schulden zijn onverwacht?}

In de memorie van toelichting staat als definitie van onverwachte schulden:

'Een onverwachte schuld is een schuld die de erfgenaam niet kende en evenmin behoorde te kennen op het moment dat hij de nalatenschap zuiver aanvaardde. Met de woorden "kende en behoren te kennen" wordt aangesloten bij het begrip goede trouw in het Burgerlijk Wetboek (artikel 3:11 BW).'26

De goede trouw wordt in dit kader als volgt uitgewerkt. De onbekendheid met de schuld mag de erfgenaam niet te verwijten zijn; voorafgaand aan de zuivere aanvaarding mag van de erfgenaam onderzoek worden gevergd, waarbij de omstandigheden van het geval de reikwijdte van de onderzoeksplicht bepalen. ${ }^{27}$ Daarbij gaat het erom wat de erfgenaam redelijkerwijs had kunnen weten op grond van een onderzoek naar waaruit de nalatenschap bestaat. Hij zal ten minste de administratie van de erflater moeten hebben geraadpleegd. Van hypotheekschulden, debetsaldi van rekeningen-courant, onbetaalde facturen en belastingschulden wordt in beginsel aangenomen dat een erfgenaam deze kende dan wel behoorde te kennen. ${ }^{28}$ Als een schuld niet uit de administratie blijkt, dan is deze niet per definitie een onverwachte schuld, omdat de erfgenaam op een andere manier weet kan hebben van de schuld, bijvoorbeeld omdat hij aanwezig was bij het aangaan van de schuld. Op de erfgenaam rust een verplichting om nader onderzoek te doen naar de schulden als de erflater niet of nauwelijks een administratie voerde.

Bij het onderzoek naar de baten en schulden van de nalatenschap, al dan niet via de administratie van de erflater, moet de erfgenaam voorzichtigheid betrachten. ${ }^{29}$ In de memorie van toelichting wordt gewaarschuwd dat de erfgenaam zich niet te rijk rekent: er is geen sprake van dwaling over de waarde van de activa van de nalatenschap als de verkoopopbrengst van een registergoed of aandelenportefeuille lager uitvalt dan aanvankelijk gedacht.

Ook als de erfgenaam weet heeft van de schuld, maar verrast wordt door de hoogte ervan is er geen sprake van een onverwachte schuld; een erfgenaam moet bij de schuldeiser navraag doen naar de exacte omvang van de schuld. ${ }^{30}$ Als een erfgenaam echter verkeerd wordt geïnformeerd door de schuldeiser en deze vordert daarna een hoger bedrag, dan kan het meerdere wel worden aangemerkt als een onverwachte schuld waarop artikel 4:194a BW ziet.

Kosten van vereffening, executele en afwikkeling van de nalatenschap (zoals een tegenvallende nota van de notaris) kwalificeren niet als onverwachte schuld: een erfgedaarom geen sprake van een onverwachte schuld.

27. Kamerstukken II 2014/15, 34224, 3, p. 17.

28. Kamerstukken II 2014/15, 34224, 3, p. 13

29. Kamerstukken II 2014/15, 34224, 3, p. 15.

30. Kamerstukken II 2014/15, 34224, 3, p. 13. naam moet rekening houden met deze kosten. Ook kan geen beroep worden gedaan op de uitzonderingsclausule als het gaat om het verdwijnen van activa in een nalatenschap bij een twee- of meertrapsmaking. ${ }^{31}$ De erfgenaam onder opschortende voorwaarde die opkomt na het in vervulling gaan van de ontbindende voorwaarde wordt volgens de memorie van toelichting beschermd door de regeling van artikel 4:190 lid $3 \mathrm{BW}$ en kan dan nog zijn keuze uitbrengen.

De kantonrechter oordeelt per geval of sprake is van een uitzonderingssituatie waarin de erfgenaam de schuld redelijkerwijs niet kon kennen. De in de memorie van toelichting vermelde voorbeelden van legitieme vorderingen vanwege een vooroverleden (stief)ouder of partner ${ }^{32}$ en een te laat gevorderde eigen bijdrage AWBZ worden dus niet in het algemeen als onverwachte schulden aangemerkt. Als voorbeelden worden verder genoemd de vordering vanwege een tijdens leven door erflater gepleegde onrechtmatige daad en andere aansprakelijkheden die uit de wet voortvloeien, zoals die van artikel 6:170 BW (aansprakelijkheid voor ondergeschikten) en artikel 6:179 BW (aansprakelijkheid voor dieren). In de memorie van toelichting wordt als onverwachte schuld ook genoemd de aan de erfgenamen onbekende Liechtensteinse stichting die erflaatster oprichtte, waarin een groot deel van het vermogen van erflaatster was ondergebracht en die leidde tot de uitspraak van de Kantonrechter Zwolle van 10 december 2010. ${ }^{33}$ Het vermogen kwam toe aan de begunstigden die door erflaatster waren aangewezen in het bij de stichting horende reglement.

Uit de toekomstige jurisprudentie moet worden afgeleid hoe de kantonrechter de onverwachte schulden en daarmee de goede trouw nader invult. Als in de toekomst de schulden steeds vaker alleen online kenbaar zullen zijn, zoals het negatieve saldo op een PayPal-rekening, schulden op online goksites en het online krediet bij webwinkels, wordt mogelijk de onderzoeksplicht van de erfgenaam van online schulden via de jurisprudentie van artikel 4:194a BW nader ingevuld. Voor de erfgenaam die geen toegang heeft tot de digitale apparaten van de erflater is namelijk onderzoek naar online schulden niet goed mogelijk.

\subsection{Gevolgen voor de afwikkeling}

Als een erfgenaam op grond van artikel 4:194a lid $1 \mathrm{BW}$ de machtiging heeft gekregen alsnog beneficiair te aan-

31. Kamerstukken II 2014/15, 34224, 2, p. 15.

32. Kamerstukken II 2014/15, 34224, 3, p. 14: erfgenamen zullen meestal van het bestaan van de legitieme vorderingen op de hoogte te zijn of geacht worden deze te kennen. Onder omstandigheden kan dit bijv. anders zijn als de geregistreerd partner van een overledene gebrouilleerd was met zijn stiefkinderen. De partner/enig erfgenaam wist niet van het bestaan van de stiefkinderen en kon daarom niet vermoeden dat de legitieme vorderingen deel uitmaken van de schulden van de nalatenschap. Kamerstukken II 2015/16, 34224, 5, p. 10: de meeste erfgenamen staan in een familieverhouding tot de erflater en zijn bekend met het vooroverlijden van de partner en de aanwezigheid van (stief)kinderen met vorderingen in dat kader.

33. Rb. Zwolle-Lelystad 10 december 2010, ECLI:NL:RBZLY:2010:BP0203. 
vaarden, dan legt hij vervolgens een verklaring van beneficiaire aanvaarding af bij de griffie van de rechtbank (art. 4:191 BW). ${ }^{34}$ De erfgenaam is dan niet langer met zijn privévermogen aansprakelijk voor de onverwachte schuld. Voor de overige erfgenamen die nog geen keuze hadden gemaakt, geldt op grond van artikel 4:194 lid 4 BW dat zij geacht worden beneficiair te aanvaarden omdat de andere erfgenaam dat (met machtiging van de kantonrechter) heeft gedaan. De erfgenaam die met machtiging van de kantonrechter beneficiair aanvaardt, betaalt griffierecht voor het verzoek en voor de beneficiaire aanvaarding die daarop volgt.

Door de beneficiaire aanvaarding moet de nalatenschap worden afgewikkeld conform de regels van de vereffening (art. 4:202 BW) en zijn alle erfgenamen vereffenaar. Mochten door een erfgenaam al schulden zijn voldaan, dan treedt die erfgenaam voor het bedrag van die schuld als schuldeiser van de nalatenschap op in de rang die deze schuld had. Voor de onverwachte schuldeiser geldt dat deze zijn positie behoudt ten opzichte van de andere schuldeisers, omdat de rangorderegelingen van artikel 3:278 lid 1 en 4:7 BW en het beginsel van de paritas creditorum onverkort gelden.

Als op grond van artikel 4:194a lid 2 BW de ontheffing is toegewezen, hoeft de verzoekende erfgenaam niet ten laste van zijn privévermogen de schuld te betalen. Voor een andere zuiver aanvaard hebbende erfgenaam die wel bekend was met de schuld kan de ontheffing betekenen dat hij een groter deel van de schuld voor zijn rekening moet nemen. ${ }^{35}$

\section{Modernisering publicatieverplichtingen en overgangsrecht}

Met de wet zijn ook wijzigingen doorgevoerd in de publicatieverplichting van artikel 4:196 en 4:206 lid 6 BW. De bekendmaking van de beneficiaire aanvaarding en de benoeming van een vereffenaar hoeft alleen nog plaats te vinden in de Staatscourant en niet ook daarnaast in nieuwsbladen.

Erfgenamen in een nalatenschap die vóór 1 september 2016 is opengevallen maar die nog geen keuze hebben gemaakt, aanvaarden de nalatenschap alleen zuiver door het verrichten van gedragingen uit het nieuwe lid 1 van artikel 4:192 BW. Erfgenamen die vóór 1 september 2016 de nalatenschap hebben aanvaard en na die datum met een onverwachte schuld worden geconfronteerd, kunnen een beroep doen op de uitzonderingsclausule van artikel 4:194a BW. ${ }^{36}$

34. De kantonrechter heeft ter zake geen discretionaire bevoegdheid, Kamerstukken II 2014/15, 34224, 3, p. 17-18.

35. Kamerstukken II 2014/15, 34224, 3, p. 16. Hier wordt naar ik aanneem gedoeld op de hoofdelijke schulden (art. 4:182 lid 2 BW)

36. Stb. 30 juni 2016, 245.

\section{Tot slot}

Door het nieuwe lid 1 van artikel 4:192 BW (de aanvaardingsfictie) aanvaarden erfgenamen de nalatenschap minder snel zuiver. Dit betekent dat er meer tijd overblijft om nog te kiezen voor beneficiaire aanvaarding. Soms hebben erfgenamen al beheershandelingen verricht voordat zij naar de notaris komen voor een verklaring van erfrecht. Als er geen goederen aan het verhaal van de schuldeisers zijn onttrokken en zij nog niet met het betalen van schulden van de nalatenschap zijn gestart, kan nog worden gekozen voor beneficiaire aanvaarding of verwerping. De huidige praktijk, met een redactionele aanpassing in de gehanteerde modellen, lijkt vooralsnog te kunnen worden voortgezet.

Omdat artikel 4:194a BW niet voor niks de 'uitzonderingsclausule' wordt genoemd, zal nog steeds beneficiaire aanvaarding worden geadviseerd voor de erfgenaam die het zekere voor het onzekere wil nemen. Nalatenschappen die van meet af aan als 'schulderfenis' te boek staan, worden sowieso beneficiair aanvaard dan wel verworpen.

De minister doet in de nota naar aanleiding van het verslag $^{37}$ een toezegging naar aanleiding van de vraag van de SP-fractie of er geen evaluatiebepaling nodig is: na de inwerkingtreding van het wetsvoorstel zal de minister 'scherp in de gaten houden' of de wijzigingen in het erfrecht zorgen voor de beoogde aanvullende bescherming van erfgenamen die zuiver hebben aanvaard en met een onverwachte schuld worden geconfronteerd. Ik houd de minister graag aan zijn woord als artikel 4:194a BW in de rechtspraktijk niet leidt tot bescherming van erfgenamen bij onverwachte schulden. 